\title{
Dietary docosahexaenoic acid-induced production of tissue lipid peroxides is not suppressed by higher intake of ascorbic acid in genetically scorbutic Osteogenic Disorder Shionogi/Shi-od/od rats
}

\author{
Seiji Sekine ${ }^{1,2}$, Kazuhiro Kubo ${ }^{1}$, Tadahiro Tadokoro ${ }^{2}$, Akio Maekawa ${ }^{2}$ and Morio Saito ${ }^{1 *}$ \\ ${ }^{1}$ Division of Food Science, Incorporated Administrative Agency, National Institute of Health and Nutrition, Toyama, \\ Shinjuku-ku, Tokyo 162-8636, Japan \\ ${ }^{2}$ Laboratory of Nutritional Biochemistry, Department of Applied Biology and Chemistry, \\ Tokyo University of Agriculture, Setagaya-ku, Tokyo 156-0054, Japan
}

(Received 14 June 2002 - Revised 19 December 2002 - Accepted 8 April 2003)

\begin{abstract}
In previous studies, we showed that docosahexaenoic acid (DHA) ingestion enhanced the susceptibility of rat liver and kidney to lipid peroxidation, but did not increase lipid peroxide formation to the level expected from the relative peroxidizability index (P-index) of the total tissue lipids. The results suggested the existence of some suppressive mechanisms against DHA-induced tissue lipid peroxide formation, as increased tissue ascorbic acid (AsA) and glutathione levels were observed. Therefore, we focused initially on the role of AsA for the suppressive mechanisms. For this purpose, we examined the influence of different levels of dietary AsA (low, moderate, high and excessive levels were 100, 300 (control), 600 and $3000 \mathrm{mg} / \mathrm{kg}$ diet respectively) on the tissue lipid peroxide and antioxidant levels in AsA-requiring Osteogenic Disorder Shionogi/Shi-od/od (ODS) rats fed DHA (6.4\% total energy) for 32 or $33 \mathrm{~d}$. Diets were pair-fed to the DHA- and $100 \mathrm{mg}$ AsA/kg diet-fed group. We found that the lipid peroxide concentrations of liver and kidney in the DHA-fed group receiving $100 \mathrm{mg}$ AsA/kg diet were significantly higher or tended to be higher than those of the DHA-fed groups with AsA at more than the usual control level of $300 \mathrm{mg} / \mathrm{kg}$ diet. Contrary to this, the liver $\alpha$-tocopherol concentration was significantly lower or tended to be lower in the DHA and $100 \mathrm{mg} \mathrm{AsA} / \mathrm{kg}$ diet-fed group than those of the other DHA-fed groups. However, tissue lipid peroxide formation and $\alpha$-tocopherol consumption were not suppressed further, even after animals received higher doses of AsA. The present results suggest that higher than normal concentrations of tissue AsA are not necessarily associated with the suppressive mechanisms against dietary DHA-induced tissue lipid peroxide formation.
\end{abstract}

Docosahexaenoic acid: Peroxidizability index: Ascorbic acid: Osteogenic Disorder Shionogi/Shi-od/od rats

Docosahexaenoic acid (22:6n-3; DHA) and eicosapentaenoic acid (20:5n-3; EPA) are the predominant $n-3$ polyunsaturated fatty acids (PUFA) in fish oils. Consumption of fish oils is particularly associated with low incidence of atherosclerosis and cardiovascular diseases, and this prophylactic effect of fish oil ingestion is attributed to $n-3$ PUFA such as EPA and DHA (Dyerberg, 1986; Herold \& Kinsella, 1986; Harris, 1989; Simopoulos, 1991; Kristensen et al. 2001; Schmidt et al. 2001). However, DHA is very prone to lipid peroxidation due to its unstable chemical structure with six double bonds. It has been reported that the relative reaction rate constants of peroxidation were $1,2,3,4$ and 5 against PUFA in which the number of methylene groups among double bonds was 1, 2, 3, 4 and 5 respectively (Cosgrove et al. 1987). The peroxidizability index $(\mathrm{P}-\mathrm{index})$ is therefore calculated according to the following equation (Cosgrove et al. 1987): P-index $=(\%$ dienoic $\times 1)+(\%$ trienoic $\times 2)+(\%$ tetraenoic $\times 3)+(\%$ pentaenoic $\times 4)+(\%$ hexaenoic $\times 5)$.

In previous studies, we showed that DHA ingestion (Saito et al. 1996; Kubo et al. 1997, 1998, 2000; Saito \& Kubo, 2003), similar to fish oil ingestion (Hammer \& Wills, 1978; Kobatake et al. 1983; Mouri et al. 1984; Song et al. 2000), enhanced the susceptibility of rat liver and kidney to lipid peroxidation and increased the requirement for vitamin E. The enhancement was a function of dietary DHA levels and was thought to be attributable to the substitution of membrane fatty acids with highly unsaturated DHA, which is very susceptible to lipid peroxidation.

However, we found in previous rat studies (Kubo et al. 1998, 2000) that dietary DHA-induced tissue lipid peroxide

Abbreviations: AsA, ascorbic acid; DHA, docosahexaenoic acid; EC, excessive-vitamin C; EPA, eicosapentaenoic acid; HC, high-level ascorbic acid; LC, low-level ascorbic acid; MC, moderate- and control-level ascorbic acid; ODS rats, Osteogenic Disorder Shionogi/Shi-od/od rats; P-index, peroxidizability index; PUFA, polyunsaturated fatty acid; TBARS, thiobarbituric acid-reactive substance.

*Corresponding author: Dr Morio Saito, fax +8133203 7584, email msaito@nih.go.jp 
formation did not increase to the level expected from the P-index of the total tissue lipids. This phenomenon was especially prominent in the liver. Moreover, the suppression of lipid peroxide formation below the P-index was also seen with EPA ingestion, but not with $\alpha$-linolenic acid ingestion (Saito \& Kubo, 2003). Therefore, in the present study, we focused on the mechanism of the suppression by DHA ingestion. With regard to this suppressive mechanism, we also found (Kubo et al. 1997; Saito \& Kubo, 2003) that the tissue ascorbic acid (AsA) and glutathione levels were increased in the rats fed DHA, and assumed that the increase in these levels might potentiate reductive-recycling of vitamin $\mathrm{E}$, leading to an augmentation of the antioxidant activity of vitamin E. In addition, AsA is known to be a potent quencher of superoxide and other reactive oxygen species, namely singlet oxygen, hydroxyl radical and peroxyl radical. Many studies (Wartanowicz et al. 1984; Kimura et al. 1992; Chakraborty et al. 1994) have already reported that AsA suppressed lipid peroxidation in vivo. Moreover, glutathione is a necessary substrate for the antioxidant enzymes glutathione $S$-transferases and glutathione peroxidases. Therefore, we presumed that the increase in dietary DHA-induced tissue AsA and glutathione levels could be part of the mechanism for suppressing tissue lipid peroxide formation below the level expected from the P-index of the total tissue lipid.

A study to clarify the suppressive mechanisms against dietary DHA-induced lipid peroxide formation is thought to be important for reasons of safety, but also to define a means of efficiently enhancing the physiological efficacy of $n$-3 PUFA.

In the present study, we focused in particular on the influence of dietary AsA levels on reducing dietary DHA-induced tissue lipid peroxidation. For this purpose, we fed graded levels of AsA together with DHA to Osteogenic Disorder Shionogi/Shi-od/od (ODS) rats. The ODS rat lacks l-gulono- $\gamma$-lactone oxidase, an enzyme that catalyses the terminal step of AsA biosynthesis (Kawai et al. 1992).

\section{Materials and methods}

\section{Animals and diets}

The experimental procedures used in the present study met the guidelines of the Animal Handling Committee for the Independent Administrative Institution, National Institute of Health and Nutrition (Tokyo, Japan).

Male ODS rats (CLEA Japan, Tokyo, Japan), 6 weeks of age and weighing 120-150 g, were housed individually in stainless-steel wire-bottomed cages kept at a constant temperature of $22 \pm 1{ }^{\circ} \mathrm{C}$ and humidity of $50-60 \%$ with a $12 \mathrm{~h}$ light-dark cycle. The composition of the experimental diets, based on the AIN-76 purified diet for rats (American Institute of Nutrition, 1977, 1980), is shown in Table 1. DHA ethyl esters (purity $920 \mathrm{~g} / \mathrm{kg}$ ) prepared from the orbital fat of tuna were donated by Maruha Corporation (Tsukuba, Japan). To prevent the autoxidation of DHA in the diets, the diet was prepared beforehand without adding DHA and was stored at $-20^{\circ} \mathrm{C}$ until use.
Table 1. Composition of the experimental diets ( $/ \mathrm{kg}$ diet) and fatty acid composition ( $\mathrm{g} / 100 \mathrm{~g}$ fatty acids) of dietary lipids*

\begin{tabular}{|c|c|c|}
\hline & Control & DHA-fed groups \\
\hline DHA (\% total energy) & 0 & $6 \cdot 4$ \\
\hline LA (\% total energy) & 8.6 & $2 \cdot 3$ \\
\hline Basic components $\dagger$ & $900 \cdot 0$ & $900 \cdot 0$ \\
\hline Test lipids $\ddagger$ & $100 \cdot 0$ & $100 \cdot 0$ \\
\hline Safflower oil & $40 \cdot 0$ & 0 \\
\hline High-oleic safflower oil & $60 \cdot 0$ & $65 \cdot 0$ \\
\hline DHA concentrate\| & 0 & $35 \cdot 0$ \\
\hline \multicolumn{3}{|l|}{ Fatty acid } \\
\hline $16: 0$ & 5.5 & 3.4 \\
\hline $18: 0$ & $2 \cdot 3$ & 1.5 \\
\hline $18: 1 n-9$ & $50 \cdot 0$ & $50 \cdot 3$ \\
\hline $18: 2 n-6(\mathrm{LA})$ & $40 \cdot 3$ & 10.9 \\
\hline $18: 3 n-3$ & 0.5 & 0.2 \\
\hline $20: 4 n-6$ & 0 & 0.6 \\
\hline $20: 5 n-3$ (EPA) & 0 & 0.9 \\
\hline $22: 5 n-3$ & 0 & 0.6 \\
\hline $22: 6 n-3(\mathrm{DHA})$ & 0 & 30.5 \\
\hline Others & 1.4 & 1.1 \\
\hline Polyunsaturated fatty acids & $40 \cdot 8$ & 43.7 \\
\hline Double-bond index§ & 1.30 & 2.66 \\
\hline Peroxidizability index§ & 41.3 & 171.6 \\
\hline
\end{tabular}

DHA, docosahexaenoic acid; LA, linoleic acid; EPA, eicosapentaenoic acid.

*The energy density of all diets was $17.4 \mathrm{MJ}(4160 \mathrm{kcal}) / \mathrm{kg}$ diet, using Atwater energy factors for energy calculation (Atwater, 1902). The vitamin $\mathrm{E}$ content of the experimental diets as $R R R$ - $\alpha$-tocopherol equivalent was $70 \mathrm{mg} / \mathrm{kg}$ diet. The ascorbic acid content of the control LA diet (DHA-free) was $300 \mathrm{mg} / \mathrm{kg}$ diet and those of the test diets (DHA-added) were 100, 300,600 and $3000 \mathrm{mg} / \mathrm{kg}$ diet.

$\dagger$ The basic components of the diet given to all the groups were as follows $(\mathrm{g} / \mathrm{kg})$ : casein 200.0, DL-methionine 3.0 , maize starch 150.0 , sucrose 225.0, glucose 225.0, cellulose powder 50.0, AIN-76 vitamin mixture (American Institute of Nutrition, 1977, 1980) 10.0, AIN-76 mineral mixture (American Institute of Nutrition, 1977) 35.0, choline bitartrate 2.0 .

‡ Fat provided $21.6 \%$ total energy.

$\S$ Calculated from the fatty acid compositions of the dietary lipids: For details, see p. 387.

\|DHA ethyl esters prepared from the ethyl esters of the orbital fat of tuna were used (Maruha Corporation, Tsukuba, Japan), the purity was $920 \mathrm{~g} / \mathrm{kg}$.

The DHA was stored at $-80^{\circ} \mathrm{C}$ and was mixed with the diet every day immediately before feeding. In a previous study (Kubo et al. 2000), we showed that dietary DHA increased tissue lipid peroxidation and decreased $\alpha$-tocopherol content in the DHA-fed group administered a diet containing $54 \mathrm{mg}$ vitamin $\mathrm{E} / \mathrm{kg}$. However, dietary vitamin E was unable to suppress lipid peroxidation, even after ingestion of a high level $(402 \mathrm{mg} / \mathrm{kg}$ diet) of vitamin E. We therefore set the dietary vitamin E level as $70 \mathrm{mg}$ $R R R$ - $\alpha$-tocopherol equivalent $/ \mathrm{kg}$ diet. The AsA content of the control linoleic acid diet was $300 \mathrm{mg} / \mathrm{kg}$ diet, and the contents of the test diets (DHA-fed groups) were 100 (low-level AsA, LC), 300 (moderate- and control-level AsA, MC), 600 (high-level AsA, HC) and 3000 (excessive-level AsA, EC) $\mathrm{mg} / \mathrm{kg}$ diet. The dietary addition of $300 \mathrm{mg} \mathrm{AsA} / \mathrm{kg}$ was enough to prevent vitamin C deficiency and to achieve maximum growth in the ODS rats (Horio et al. 1985). Therefore, the dietary AsA level of the control group was $300 \mathrm{mg} \mathrm{AsA} / \mathrm{kg}$ diet. The fatty acid composition ( $\mathrm{g} / 100 \mathrm{~g}$ fatty acids) of dietary lipids is also shown in Table 1. The proportion of total PUFA was at almost the same level in the control linoleic acid and four DHA-fed groups. The degree of unsaturation of dietary lipids is presented as the double-bond index (Pietrangelo et al. 1990) and P-index (Cosgrove 
et al. 1987). The P-index was calculated according to the following equation: $\mathrm{P}$-index $=(\%$ dienoic $\times 1)+(\%$ trienoic $\times 2)+(\%$ tetraenoic $\times 3)+(\%$ pentaenoic $\times 4)$ $+(\%$ hexaenoic $\times 5)$.

After the rats were fed a basal diet containing $50 \mathrm{~g}$ higholeic safflower oil $/ \mathrm{kg}$ diet for $5 \mathrm{~d}$, six rats from each group were fed the experimental diets for $33 \mathrm{~d}$ in the LC group or $32 \mathrm{~d}$ in all the other groups. Water was consumed ad libitum. Diets were pair-fed to the LC group. During the supplementation period, each diet was made available to the rats in the evening and was removed the next morning. After being deprived of food overnight, the rats were killed by cardiac puncture. The tissues were promptly excised, washed with isotonic saline $(9 \mathrm{~g} \mathrm{NaCl} / \mathrm{l})$ and weighed. The liver was then perfused with ice-cold isotonic saline via the portal vein. Samples of liver, kidney and testis were stored at $-80^{\circ} \mathrm{C}$ until used for the analysis. Sodium citrate was used as an anticoagulant, and the plasma was separated by centrifugation at $2700 \mathrm{~g}$ for $15 \mathrm{~min}$ at $4^{\circ} \mathrm{C}$.

\section{Determination of lipid peroxides}

When lipid peroxidation occurs, polyunsaturated lipids are initially oxidized to primary products of lipid peroxidation such as lipid hydroperoxides via conjugated diene formation. The primary products then decompose to secondary products such as aldehydes. Aldehydes react with amino compounds, and produce the end products of lipid peroxidation, such as lipofuscin. For the present study, we determined the primary products of lipid peroxidation (i.e. plasma lipid hydroperoxides, tissue conjugated dienes and chemiluminescence emission), the secondary products (i.e. plasma and tissue thiobarbituric acid-reactive substances (TBARS)) and the endproducts (i.e. plasma water-soluble fluorescent substance and liver microsomal lipofuscin). The plasma lipid hydroperoxide concentration was determined using a lipid hydroperoxide assay kit (Determiner LPO; Kyowa Medex Co., Ltd, Tokyo, Japan). The determination utilized haemoglobin as the catalyst of the reaction, in which lipid hydroperoxide and a Methylene Blue-derivative react, and equimolar Methylene Blue is produced. The Methylene Blue was measured at $675 \mathrm{~nm}$. Conjugated dienes in the liver, kidney and testis were determined by the method of $\mathrm{Hu}$ et al. (1989) and Rao \& Recknagel (1968). The conjugated dienes were measured at $233 \mathrm{~nm}$ using an extinction coefficient of $27000(\mathrm{~mol} / \mathrm{l})^{-1} \cdot \mathrm{cm}^{-1}$.

The tissue chemiluminescence intensities of the homogenates were determined according to the method of Miyazawa et al. (1984). The light emitted from the homogenates is due mainly to singlet molecular oxygen and/or excited carbonyl compounds resulting from the breakdown of lipid peroxyradicals (Boveris et al. 1981; Miyazawa et al. 1984), which are produced in the early stage of peroxidation.

The plasma TBARS were determined by the method of Yagi (1976). As an antioxidant, butylated hydroxytoluene was added to the reaction mixture at a final concentration of $0.36 \mathrm{~mm}$. The tissue TBARS were measured according to the method of Ohkawa et al. (1979) with a minor modification, in which butylated hydroxytoluene was added to the reaction mixture at a final concentration of $0.45 \mathrm{~mm}$. TBARS are expressed in terms of the malondialdehyde equivalent. This method measures primarily malondialdehyde, alkenals and alkadienals produced at acidic and heating conditions of the assay.

The plasma water-soluble fluorescent substances were analysed by the method of Tsuchida et al. (1985). Liver microsomes were prepared (Saito \& Yamaguchi, 1988) and the microsomal lipofuscin concentration was determined by the method of Fletcher et al. (1973).

\section{Determination of antioxidants}

$\alpha$-Tocopherol concentrations in the test lipids, plasma and tissues were analysed by HPLC as described by Saito et al. (1992). AsA levels in the tissues were analysed by the method of Roe et al. (1948). Non-protein sulfhydryl (mostly glutathione) levels in the tissues were analysed by the method of Beutler et al. (1963). Dehydroascorbic acid reductases are primarily categorized as glutathionedependent glutaredoxin and NADPH-dependent thioredoxin reductase. Glutaredoxin and thioredoxin reductase activities were determined as follows. Liver homogenate $(250 \mathrm{~g} / \mathrm{kg})$ was prepared in ice-cold $0.1 \mathrm{M}$-potassium phosphate buffer, $\mathrm{pH} 6 \cdot 85$. The homogenate was centrifuged at $20000 \mathrm{~g}$ for $15 \mathrm{~min}$ at $4^{\circ} \mathrm{C}$, and the supernatant fraction was further centrifuged at $105000 \mathrm{~g}$ for $60 \mathrm{~min}$ at $4^{\circ} \mathrm{C}$. The resultant cytosolic fraction was used for the glutaredoxin (Wells et al. 1995) and thioredoxin reductase (Holmgren \& Björnstedt, 1995) assays. One unit of glutaredoxin activity was defined as the amount of enzyme that reduced $1 \mu \mathrm{mol}$ dehydroascorbic acid in $1 \mathrm{~min}$ at $30^{\circ} \mathrm{C}$. One unit of thioredoxin reductase activity was defined as $1 \mu \mathrm{mol}$ $5^{\prime}$-thionitrobenzoic acid formed per min.

The cytosolic protein content was measured by the method of Lowry et al. (1951).

\section{Plasma aspartate aminotransferase and alanine aminotransferase assays}

The activities of aspartate aminotransferase and alanine aminotransferase in the plasma were determined using a clinical enzyme assay kit (Wako Pure Chemical Ind., Osaka, Japan) by the method of Reitman \& Frankel (1957).

\section{Fatty acid composition analysis}

Total lipids in the liver were extracted according to the method of Folch et al. (1957). Total lipids in the kidney and testis were extracted according to the method of Bligh \& Dyer (1959). Fatty acid methyl esters of dietary lipids and total tissue lipids were prepared according to Kubo et al. (2000). The methyl esters were analysed by GLC with a flame ionization detector (Shimadzu GC$18 \mathrm{~A}$, Kyoto, Japan) by using a $25 \mathrm{~m} \times 0.25 \mathrm{~mm}$ internal diameter HR-SS-10 capillary column (Shinwa Chemical Industries Ltd, Kyoto, Japan). The temperature of the column oven was programmed from 160 to $210^{\circ} \mathrm{C}$ at a rate of $2.0^{\circ} \mathrm{C} / \mathrm{min}$. Injector and detector temperatures were $250^{\circ} \mathrm{C}$. The carrier gas was $\mathrm{He}$. 


\section{Statistical analysis}

All results were expressed as means values and standard deviations. Significant differences between the mean values of the control and MC group were evaluated by Student's $t$ test (Dixon \& Massey, 1983). Significant differences among the mean values of the DHA-fed groups were evaluated by ANOVA coupled with Bonferroni's multiple comparison. For clarifying differences between the increases in the relative tissue lipid peroxide levels and the relative $\mathrm{P}$-index, significant differences between the relative ratios of the lipid peroxide levels to the control values and those of P-index were also compared by Student's $t$ test. The limit of significance was set at $P<0 \cdot 05$.

\section{Results}

In the rats of the LC group, signs of scurvy, such as haemorrhages around the eyes and nose, did not appear during the $33 \mathrm{~d}$ of the experimental period. The body-weight gain, food intake, and relative kidney and testis weights did not differ significantly among the treatment groups (results not shown). Relative liver weight did not significantly differ between the control group and DHA-fed
MC group (34 (SD 2) v. 34 (SD 1) g/kg body weight respectively). When the DHA-fed groups were compared, the relative liver weight of the LC group was significantly higher than that of EC group (36 (SD 2) v. 32 (SD 2) g/ kg body weight respectively, $P<0.05)$.

The major PUFA compositions of total lipids in the liver, kidney and testis are shown in Table 2 . In the liver, the proportions of linoleic acid $(18: 2 n-6)$ and arachidonic acid $(20: 4 n-6)$ were significantly higher $(P<0 \cdot 05)$ in the control group than in the DHA-fed MC group, but those of EPA $(20: 5 n-3)$ and DHA were higher in the DHA-fed MC group than in the control. When the proportions of those PUFA were compared among the DHA-fed groups, all proportions varied within a small range, and the variation was negligible. The double-bond index and P-index were significantly higher $(P<0 \cdot 05)$ in the DHA-fed MC group than in the control group, but no significant difference was noticed among the DHA-fed groups. The liver P-index of total lipids in the DHA-fed groups was 1.6- to 1.7-fold higher than that of the control group.

In the kidney, the proportion of arachidonic acid was significantly lower $(P<0.05)$, but linoleic acid, EPA (22:5n-3) and DHA were higher, in the DHA-fed MC group than in the control group. Moreover, the proportion of EPA was comparable with that of DHA achieved by

Table 2. Major polyunsaturated fatty acid compositions $(\mathrm{g} / 100 \mathrm{~g}$ ) of total lipids in the liver, kidney and testis of Osteogenic Disorder Shionogi/Shi-od/od (ODS) rats fed docosahexaenoic acid (DHA) and graded levels of ascorbic acid $†$

(Mean values and standard deviations for six rats per group)

\begin{tabular}{|c|c|c|c|c|c|c|c|c|c|c|}
\hline & & & \multicolumn{8}{|c|}{ DHA-fed groups } \\
\hline & \multicolumn{2}{|c|}{ Control } & \multicolumn{2}{|c|}{ LC } & \multicolumn{2}{|c|}{ MC } & \multicolumn{2}{|c|}{$\mathrm{HC}$} & \multicolumn{2}{|c|}{$\mathrm{EC}$} \\
\hline & Mean & SD & Mean & SD & Mean & SD & Mean & SD & Mean & SD \\
\hline \multicolumn{11}{|l|}{ Liver } \\
\hline $18: 2 n-6(\mathrm{LA})$ & $12 \cdot 9$ & 1.9 & $8 \cdot 3$ & 0.5 & $8 \cdot 2^{*}$ & 0.4 & $8 \cdot 3$ & 0.3 & $8 \cdot 6$ & 0.7 \\
\hline $20: 4 n-6$ & $13 \cdot 8$ & 1.6 & $3 \cdot 7^{a b}$ & 0.3 & $3 \cdot 3^{a *}$ & 0.3 & $3 \cdot 4^{\mathrm{ab}}$ & 0.3 & $3 \cdot 7^{b}$ & $0 \cdot 2$ \\
\hline $22: 5 n-3$ & 0.3 & 0.1 & $1 \cdot 4^{b}$ & $0 \cdot 2$ & $1 \cdot 2^{\mathrm{ab} *}$ & 0.2 & $1 \cdot 1^{\mathrm{a}}$ & $0 \cdot 1$ & $1 \cdot 2^{\mathrm{ab}}$ & $0 \cdot 2$ \\
\hline $22: 6 n-3(\mathrm{DHA})$ & 1.9 & 0.7 & $18 \cdot 4$ & $1 \cdot 2$ & $17 \cdot 6^{\star}$ & $2 \cdot 8$ & $17 \cdot 5$ & $1 \cdot 0$ & 18.4 & $1 . \overline{7}$ \\
\hline Double-bond index $\ddagger$ & 1.4 & 0.1 & 1.9 & 0.1 & $1 \cdot 8^{*}$ & 0.2 & 1.9 & 0.1 & 1.9 & $0 \cdot 1$ \\
\hline Peroxidizability index $\ddagger$ & $77 \cdot 8$ & 6.9 & $132 \cdot 7$ & $7 \cdot 8$ & $122 \cdot 4^{*}$ & $15 \cdot 8$ & $123 \cdot 6$ & $5 \cdot 4$ & $129 \cdot 5$ & $9 \cdot 1$ \\
\hline \multicolumn{11}{|l|}{ Kidney } \\
\hline $18: 2 n-6(\mathrm{LA})$ & 9.5 & 0.3 & $10 \cdot 5$ & 0.7 & $11 \cdot 1^{*}$ & 0.3 & $11 \cdot 1$ & 0.5 & $11 \cdot 0$ & 0.4 \\
\hline $20: 4 n-6$ & $23 \cdot 9$ & $3 \cdot 2$ & $9 \cdot 1^{\mathrm{a}}$ & $1 \cdot 1$ & $10 \cdot 9^{b *}$ & 0.4 & $10 \cdot 9^{b}$ & 0.8 & $10 \cdot 6^{\mathrm{ab}}$ & 1.0 \\
\hline $20: 5 n-3$ (EPA) & 0.1 & 0.1 & $6 \cdot 9$ & 0.8 & $7 \cdot 6^{\star}$ & 0.6 & $7 \cdot 3$ & 0.6 & $6 \cdot 8$ & 0.9 \\
\hline $22: 5 n-3$ & 0.2 & 0.1 & 0.5 & $0 \cdot 1$ & $0 \cdot 6^{*}$ & 0.1 & 0.6 & 0.1 & 0.5 & $0 \cdot 1$ \\
\hline Double-bond index $\ddagger$ & $1 . \overline{6}$ & 0.1 & $1 \cdot 6$ & 0.1 & $1 \cdot 8^{*}$ & 0.1 & $1 \cdot 8$ & 0.1 & $1 \cdot 7$ & $0 \cdot 1$ \\
\hline Peroxidizability index $\ddagger$ & $96 \cdot 9$ & $11 \cdot 3$ & $105 \cdot 0$ & $11 \cdot 1$ & $118 \cdot 0^{*}$ & $4 \cdot 8$ & $116 \cdot 0$ & $6 \cdot 0$ & $110 \cdot 4$ & $9 \cdot 5$ \\
\hline \multicolumn{11}{|l|}{ Testis } \\
\hline $18: 2 n-6(L A)$ & $11 \cdot 6$ & $4 \cdot 0$ & $6 \cdot 0$ & $2 \cdot 2$ & $7 \cdot 0^{\star}$ & $1 \cdot 3$ & $6 \cdot 7$ & $1 \cdot 2$ & $6 \cdot 3$ & 1.5 \\
\hline $20: 4 n-6$ & $7 \cdot 3$ & 2.4 & $6 \cdot 9$ & $2 \cdot 3$ & $5 \cdot 0$ & 1.9 & $5 \cdot 5$ & $2 \cdot 2$ & $6 \cdot 3$ & $2 \cdot 1$ \\
\hline $20: 5 n-3$ (EPA) & 0.0 & 0.1 & 0.2 & 0.3 & 0.4 & 0.2 & 0.3 & 0.3 & 0.3 & 0.3 \\
\hline $22: 5 n-6$ & $9 \cdot 6$ & 3.6 & $8 \cdot 7$ & $3 \cdot 6$ & $8 \cdot 0$ & $3 \cdot 0$ & 8.5 & 3.9 & $9 \cdot 5$ & 3.4 \\
\hline $22: 6 n-3(\mathrm{DHA})$ & 0.6 & 0.3 & $4 \cdot 8$ & $2 \cdot 0$ & $6 \cdot 6^{*}$ & $1 \cdot 1$ & $6 \cdot 1$ & 1.4 & $5 \cdot 4$ & 1.4 \\
\hline Double-bond index $\ddagger$ & 1.6 & 0.2 & $1 \cdot 7$ & $0 \cdot 2$ & $1 \cdot 7$ & 0.1 & $1 \cdot 7$ & 0.2 & $1 \cdot 7$ & 0.1 \\
\hline Peroxidizability index $\ddagger$ & $89 \cdot 0$ & $21 \cdot 3$ & $111 \cdot 8$ & $19 \cdot 1$ & $102 \cdot 8$ & $16 \cdot 2$ & $100 \cdot 1$ & $17 \cdot 9$ & $104 \cdot 6$ & $17 \cdot 5$ \\
\hline
\end{tabular}

DHA, docosahexaenoic acid; LC, low-level ascorbic acid; MC, moderate-level ascorbic acid; HC, high-level ascorbic acid; EC, excessive-level ascorbic acid; LA, linoleic acid; EPA, eicosapentaenoic acid.

${ }^{a, b}$ Mean values for the DHA-fed groups of each tissue within a row with unlike superscript letters were significantly different (ANOVA coupled with Bonferroni's multiple comparison, $P<0.05$ )

Mean values were significantly different from those of the control group (Student's $t$ test): ${ }^{\star} P<0.05$.

†For details of diets and procedures, see Table 1 and p. 386.

$\ddagger$ Calculated from the fatty acid compositions of the tissue total lipids: For details, see p. 387. 
DHA ingestion. The variations of proportions of PUFA among the DHA-fed groups were negligible. Both the double-bond index and P-index were significantly higher $(P<0.05)$ in the DHA-fed MC group than in the control group, but no significant difference was noticed among the DHA-fed groups. The P-index of total lipids in the DHA-fed groups was 1.1- to 1.2-fold greater than the control value, and the increase was slight.

In the testis, the proportion of linoleic acid was significantly lower $(P<0.05)$ in the DHA-fed MC group than in the control group, and that of arachidonic acid did not differ significantly between the control and DHA-fed MC groups. The proportion of DHA was significantly higher $(P<0.05)$ in the DHA-fed MC group than in the control group, but the proportions of arachidonic acid, EPA and 22:5n-6 did not differ significantly. None of the proportions of the major PUFA differed significantly among the DHA-fed groups. The double-bond index and P-index did not differ significantly among any of the groups, even after the highly unsaturated DHA was administered to the rats. The P-index of total lipids in the DHAfed groups was $1 \cdot 1$ - to $1 \cdot 3$-fold greater than the control value, and this increase was determined to be slight.

When the liver, kidney and testis were compared, the proportion of DHA was highest in the liver of the DHAfed groups. In the kidney, the proportion of arachidonic acid was high and was maintained at high proportions even after DHA was ingested. In the testis, highly unsaturated $n-6$ fatty acids, particularly $22: 5 n-6$, were in high proportions, and even in the DHA-fed groups, the proportion of $22: 5 n-6$ was higher than that of DHA.

The plasma lipid hydroperoxide concentrations did not differ significantly among any of the treatment groups (results not shown). The TBARS level was significantly higher $(P<0.05)$ in the DHA-fed MC group than in the control group (Table 3 ), but no significant difference was noticed among the DHA-fed groups. Hence, the increased levels of dietary AsA did not affect the TBARS concentration. The water-soluble fluorescent substance level was significantly higher $(P<0.05)$ in the DHA-fed MC group than in the control group, and was slightly but significantly lower $(P<0.05)$ in the MC group than in the EC group when the DHA-fed groups were compared (Table 3 ). The plasma $\alpha$-tocopherol concentration of the DHA-fed MC group was significantly lower $(P<0.05)$ than that of the control group, but no significant difference was noticed among the DHA-fed groups (Table 3). The aspartate aminotransferase activity did not differ significantly in any of the treatment groups (Table 3). However, the alanine aminotransferase activity was greater in the MC group than in the control group, and was suppressed slightly in the HC and EC groups, according to the DHA-fed group comparisons (Table 3). Thus, tissue parenchymal cell injury was demonstrated in the LC and MC groups, and was suppressed by a relatively increased intake of AsA. Such injury was not paralleled by the lipid peroxide and $\alpha$-tocopherol concentrations in the plasma and in the tissue, as will be described later.

The lipid peroxide levels in the liver and kidney are shown in Table 4, and the relationship between the $\mathrm{P}$-index and lipid peroxide levels in the tissues expressed relative to the control values is shown in Fig. 1. In the liver, the conjugated diene level did not differ significantly among any of the treatment groups (Fig. 1(A)). The chemiluminescence intensity was significantly higher $(P<0.05)$ in the DHA-fed MC group than in the control group. When the DHA-fed groups were compared, the intensity tended to be higher $(P=0.0937)$ in the LC group than in the $\mathrm{MC}, \mathrm{HC}$ and $\mathrm{EC}$ groups (Table 4 and Fig. 1(A)), although no significant difference in the intensity was noticed among the DHA-fed groups. The liver TBARS levels showed a tendency similar to that of the

Table 3. Influence of graded levels of dietary ascorbic acid on concentrations of thiobarbituric acid-reactive substances (TBARS), water-soluble fluorescent substance and $\alpha$-tocopherol, and on activities of aspartate aminotransferase (AST) and alanine aminotransferase $(\mathrm{ALT})$ in plasma of Osteogenic Disorder Shionogi/Shi-od/od (ODS) rats fed docosahexaenoic acid (DHA)†

(Mean values and standard deviations for six rats per group)

\begin{tabular}{|c|c|c|c|c|c|c|c|c|c|c|}
\hline \multirow{6}{*}{$\begin{array}{l}\text { DHA (\% total energy) } \\
\text { LA (\% total energy) } \\
\text { AsA (mg/kg diet) }\end{array}$} & & & \multicolumn{8}{|c|}{ DHA-fed groups } \\
\hline & \multicolumn{2}{|c|}{ Control } & \multicolumn{2}{|c|}{ LC } & \multicolumn{2}{|c|}{ MC } & \multicolumn{2}{|c|}{$\mathrm{HC}$} & \multicolumn{2}{|c|}{$\mathrm{EC}$} \\
\hline & \multicolumn{2}{|c|}{0} & \multicolumn{2}{|c|}{$6 \cdot 4$} & \multicolumn{2}{|c|}{6.4} & \multicolumn{2}{|c|}{$6 \cdot 4$} & \multicolumn{2}{|c|}{$6 \cdot 4$} \\
\hline & 8. & & & & 2. & & & & & \\
\hline & \multicolumn{2}{|c|}{300} & \multicolumn{2}{|c|}{100} & \multicolumn{2}{|c|}{300} & \multicolumn{2}{|c|}{600} & \multicolumn{2}{|c|}{3000} \\
\hline & Mean & SD & Mean & SD & Mean & SD & Mean & SD & Mean & SD \\
\hline TBARS ( $\mu \mathrm{mol}$ MDA/l) & 3.0 & 0.3 & $4 \cdot 1$ & 0.4 & $5 \cdot 2^{*}$ & $1 \cdot 2$ & 4.2 & 0.6 & 4.1 & 0.4 \\
\hline $\begin{array}{l}\text { Water-soluble fluorescent substance (relative fluorescence } \\
\text { intensity) } \ddagger\end{array}$ & $3 \cdot 1$ & 0.3 & $4 \cdot 1^{\mathrm{ab}}$ & 0.1 & $3 \cdot 8^{a *}$ & 0.2 & $4 \cdot 2^{\mathrm{ab}}$ & 0.4 & $4 \cdot 5^{\mathrm{b}}$ & 0.4 \\
\hline$\alpha$-Tocopherol $(\mu \mathrm{mol} / \mathrm{l})$ & $16 \cdot 9$ & 3.5 & $7 \cdot 7$ & 0.7 & $7 \cdot 3^{*}$ & 1.8 & $7 \cdot 2$ & $1 \cdot 3$ & $7 \cdot 6$ & 1.5 \\
\hline AST $(\mu \mathrm{kat} / \mathrm{l})$ & 0.34 & 0.06 & 0.40 & 0.08 & 0.36 & 0.02 & 0.37 & 0.05 & 0.35 & 0.02 \\
\hline ALT ( $\mu \mathrm{kat} / \mathrm{l})$ & 0.04 & 0.02 & $0 \cdot 10^{\mathrm{b}}$ & 0.03 & $0.08^{\mathrm{ab}}$ & 0.01 & $0.06^{a}$ & 0.01 & $0.06^{\mathrm{a}}$ & 0.02 \\
\hline
\end{tabular}

LC, low-level ascorbic acid; MC, moderate-level ascorbic acid; HC, high-level ascorbic acid; EC, excessive-level ascorbic acid; LA, linoleic acid; AsA, ascorbic acid; MDA, malondialdehyde.

${ }^{a, b}$ Mean values for the DHA-fed groups within a row with unlike superscript letters were significantly different (ANOVA coupled with Bonferroni's multiple comparison, $P<0.05)$

Mean values were significantly different from those of the control group (Student's $t$ test): ${ }^{*} P<0.05$.

†For details of diets and procedures, see Table 1 and p. 386.

¥ The instrument was calibrated to read 100 relative fluorescence units against a quinine sulfate solution $\left(0.128 \mu \mathrm{mol} / \mathrm{l} 50 \mathrm{mM}-\mathrm{H}_{2} \mathrm{SO}_{4}\right)$. 
Table 4. Influence of graded levels of dietary ascorbic acid on liver and kidney chemiluminescence intensities and thiobarbituric acid-reactive substance (TBARS) levels, and liver microsomal lipofuscin level in Osteogenic Disorder Shionogi/Shi-od/od (ODS) rats fed docosahexaenoic acid (DHA)†

(Mean values and standard deviations for six rats per group)

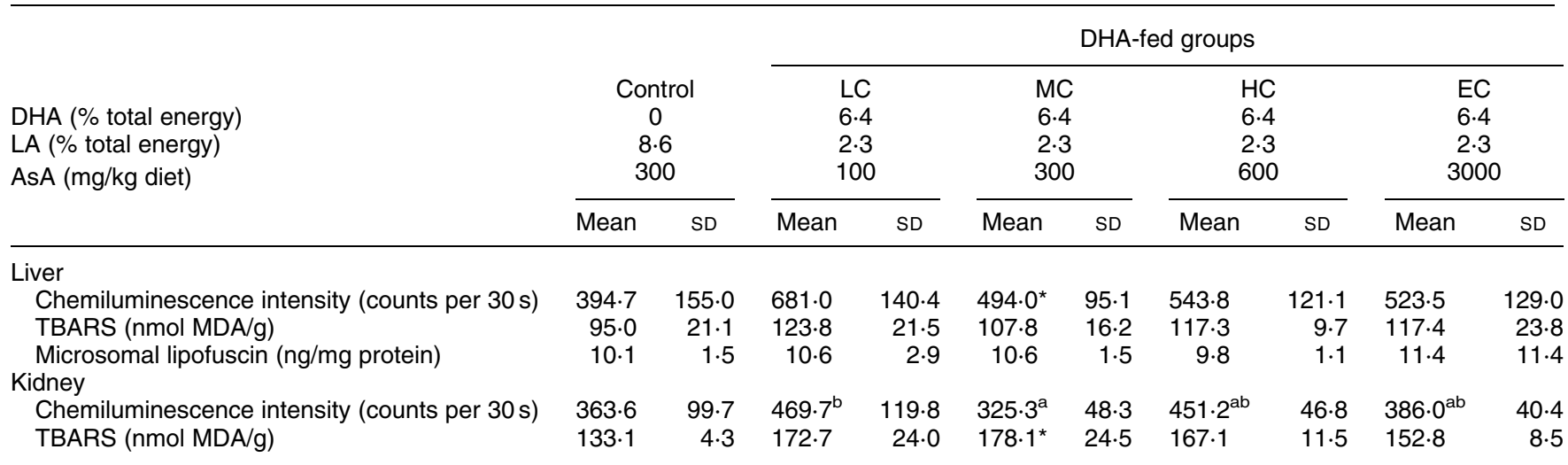

LC, low-level ascorbic acid; MC, moderate-level ascorbic acid; HC, high-level ascorbic acid; EC, excessive-level ascorbic acid; LA, linoleic acid; AsA, ascorbic acid; MDA, malondialdehyde.

${ }^{a, b}$ Mean values for the DHA-fed groups within a row with unlike superscript letters were significantly different (ANOVA coupled with Bonferroni's multiple comparison, $P<0.05$ )

Mean values were significantly different from those of the control group (Student's $t$ test): ${ }^{\star} P<0.05$.

†For details of diets and procedures, see Table 1 and p. 386

chemiluminescence intensity, but the values did not differ significantly among the treatment groups (Table 4 and Fig. 1(A)). The liver microsomal lipofuscin levels did not differ significantly among any of the treatment groups (Table 4 and Fig. 1(A)). When the liver lipid peroxides and P-index expressed relative to the control values were compared, only the chemiluminescence intensities in the LC and HC groups coincided with the P-index, and the other lipid peroxides in each DHA-fed group were significantly lower $(P<0 \cdot 05)$ than each P-index (Fig. 1(A)).

In the kidney, the conjugated diene levels did not differ significantly among any of the treatment groups (Fig. 1(B)). The chemiluminescence intensity did not differ significantly between the control and DHA-fed MC groups, but when the DHA-fed groups were compared, the intensity was significantly lower $(P<0.05)$ in the MC group than in the LC group (Table 4 and Fig. 1(B)). The TBARS level was significantly higher $(P<0.05)$ in the DHA-fed MC group than in the control group. When the TBARS levels of DHA-fed groups were compared, the level did not differ significantly. When the lipid peroxides and $\mathrm{P}$-index expressed relative to the control values were compared, the conjugated diene levels in the $\mathrm{MC}$ and $\mathrm{HC}$ groups and the chemiluminescence intensity in the $\mathrm{MC}$ group were significantly lower $(P<0.05)$ than each P-index (Fig. 1(B)). Contrary to this, the TBARS level in the LC group was significantly higher $(P<0.05)$ than the P-index. No other significant differences between the TBARS levels and each P-index were observed.

In the testis, the conjugated diene level and TBARS level did not differ significantly among any of the treatment groups (Fig. 1(C)). The chemiluminescence intensity was significantly higher $(P<0.05)$ in the DHA-fed MC group than in the control group, but no significant difference was noticed when the DHA-fed groups were compared (Fig. 1(C)). When the lipid peroxides and P-index expressed relative to the control values were compared, those values nearly coincided in each group except that the conjugated diene level of the LC group was significantly $(P<0.05)$ lower than the P-index.

The tissue antioxidant levels are shown in Fig. 2. In the liver, the $\alpha$-tocopherol level was significantly lower $(P<0.05)$ in the DHA-fed MC group than in the control group. When the DHA-fed groups were compared, the $\alpha$ tocopherol level in the LC group was significantly lower $(P<0.05)$ than in the MC group. However, no significant difference was noticed among the $\mathrm{MC}, \mathrm{HC}$ and EC groups (Fig. 2(A)). Therefore, a vitamin E-sparing effect by dietary AsA intake $\geq 300 \mathrm{mg} / \mathrm{kg}$ diet was observed. The AsA level was significantly lower $(P<0.05)$ in the DHA-fed MC group than in the control group, but it increased with an increase in the dietary AsA levels in the DHA-fed groups. The liver glutathione levels and glutaredoxin activities (results not shown) did not differ significantly among the treatment groups. The liver thioredoxin reductase activities were $48 \cdot 3$ (SD 3.2), 41.1 (SD 3.6), 44.6 (SD 2.5), $46 \cdot 6$ (SD 1.7) and 43.3 (SD 6.3) units/mg protein in the control, LC, MC, $\mathrm{HC}$ and EC groups respectively. The activity was significantly lower $(P<0 \cdot 05)$ in the MC group than in the control, but no significant difference was noticed among the DHAfed groups.

In the kidney, the $\alpha$-tocopherol level was significantly lower $(P<0.05)$ in the MC group than in the control group (Fig. 2(B)). When the DHA-fed groups were compared, the levels did not differ significantly. Hence, the $\alpha$-tocopherol level was not influenced by a higher intake of AsA. The AsA level did not differ significantly between the control and $\mathrm{MC}$ groups, but did increase with increasing the dietary AsA levels, as shown by comparison of the DHA-fed groups (Fig. 2(B)). The glutathione level did not differ significantly among any of the treatment groups (Fig. 2(B)).

In the testis, the $\alpha$-tocopherol level was significantly lower in the MC group than in the control (Fig. 2(C)). However, when the DHA-fed groups were compared, no influence of 

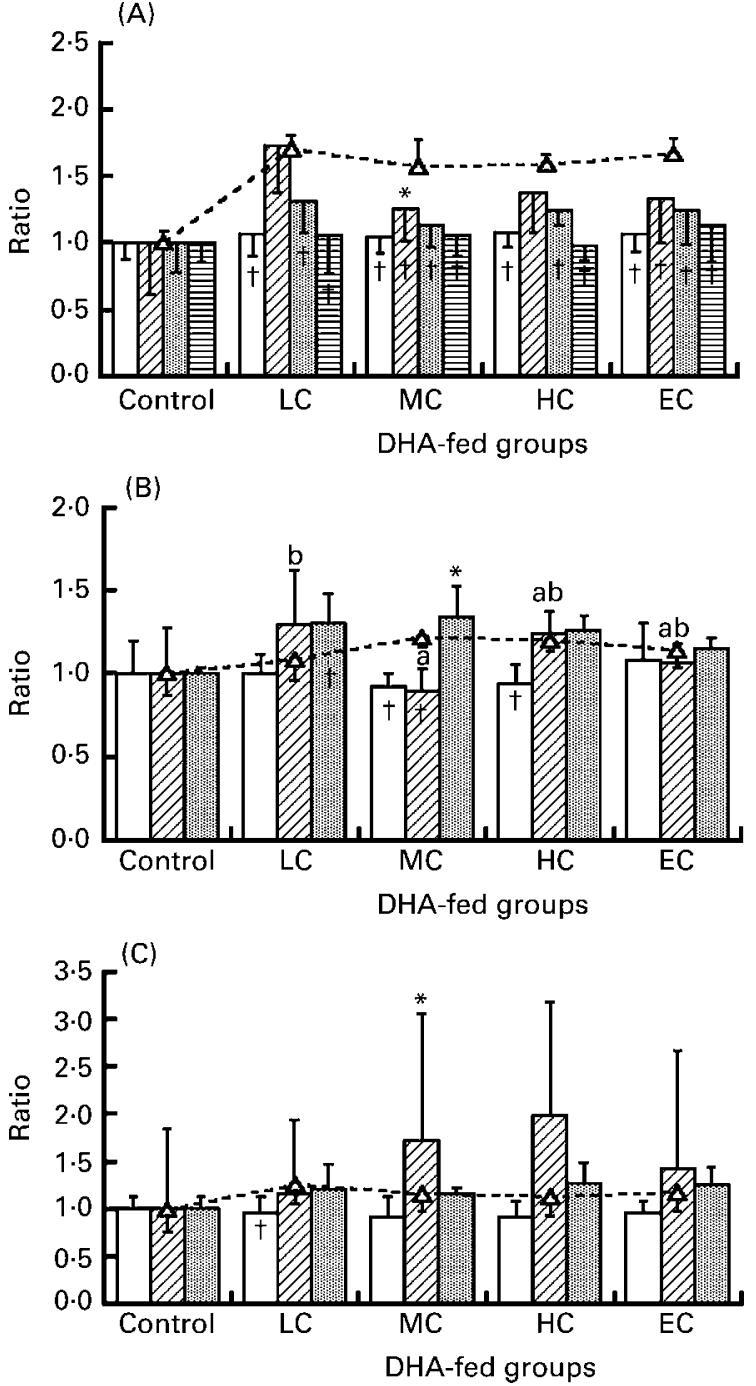

Fig. 1. Lipid peroxide levels and peroxidizability indices (P-index) of total lipids expressed relative to the control values in the liver (A), kidney (B) and testis (C) of Osteogenic Disorder Shionogi/Shi-od/od (ODS) rats fed docosahexaenoic acid (DHA) and graded levels of ascorbic acid. The relative P-index was used in the present study as an indicator to determine the vulnerability of tissue lipids to oxidation. The P-index of total lipids was calculated according to the following equation (Cosgrove et al. 1987): P-index $=(\%$ dienoic $\times 1)+(\%$ trienoic $\times 2)+(\%$ tetraenoic $\times 3)+(\%$ pentaenoic $\times 4)$ $+(\%$ hexaenoic $\times 5)$. The ascorbic acid content of the control linoleic acid diet (DHA-free) was $300 \mathrm{mg} / \mathrm{kg}$ and those of the test diets (DHA-added) were 100 (low-level ascorbic acid, LC), 300 (moderate-level ascorbic acid, MC), 600 (high-level ascorbic acid, HC) and 3000 (excessive-level ascorbic acid, EC) mg/kg diet. $\square$, Conjugated

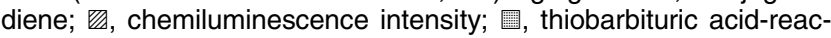
tive substances; 目, lipofuscin; $-\Delta-$, P-index. For details of diets and procedures, see Table 1 and p. 386. Values are means with standard deviations shown by vertical bars (six per group). ${ }^{\mathrm{a}, \mathrm{b}}$ Mean values with unlike superscript letters were significantly different (ANOVA and Bonferroni's multiple comparison $P<0.05$ ). Mean values were significantly different from those of the control group (Student's $t$ test): ${ }^{\star} P<0.05$. Mean values for the relative ratio of lipid P-index were significantly different from those for lipid peroxide in each group (Student's $t$ test): $† P<0.05$.

dietary AsA levels was observed; these results were similar to those of the kidney (Fig. 2(B)). The AsA level did not differ significantly between the control and MC groups, but increased with increasing the dietary AsA levels,
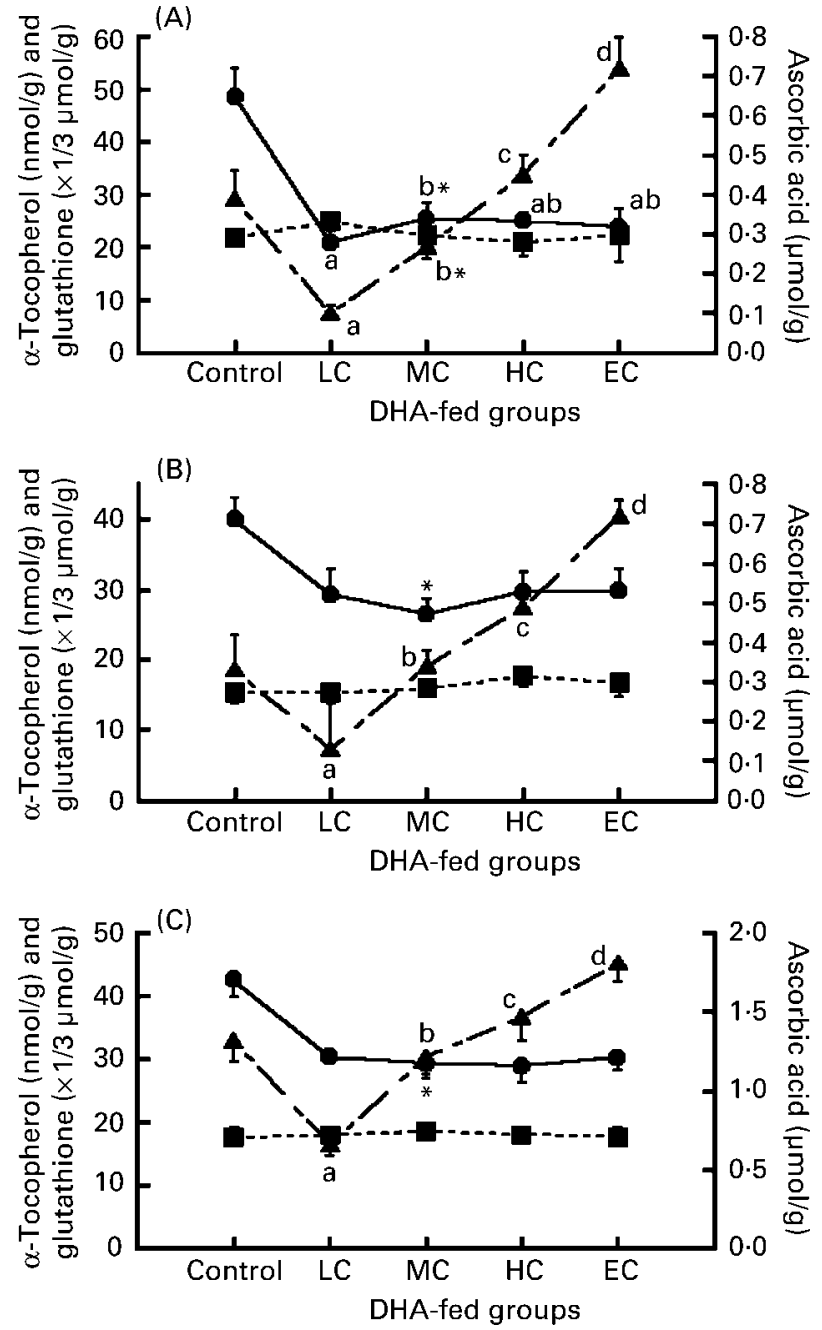

Fig. 2. Changes in $\alpha$-tocopherol $(\bullet)$, ascorbic acid $(\boldsymbol{\Delta})$ and glutathione $(\boldsymbol{D})$ levels in the liver $(A)$, kidney $(B)$ and testis $(C)$ of Osteogenic Disorder Shionogi/Shi-od/od (ODS) rats fed docosahexaenoic acid (DHA) and graded levels of ascorbic acid. The ascorbic acid content of the control linoleic acid diet (DHA-free) was $300 \mathrm{mg} / \mathrm{kg}$ and those of the test diets (DHA-added) were 100 (low-level ascorbic acid, LC), 300 (moderate-level ascorbic acid, MC), 600 (high-level ascorbic acid, HC) and 3000 (excessive-level ascorbic acid, EC) $\mathrm{mg} / \mathrm{kg}$ diet. Values are means with standard deviations shown by vertical bars (six per group). ${ }^{a, b, c, d}$ Mean values with unlike superscript letters were significantly different (ANOVA and Bonferroni's multiple comparison, $P<0.05)$. Mean values were significantly different from those of the control group (Student's $t$ test): * $P<0.05$.

according to the DHA-fed group comparisons (Fig. 2(C)). The AsA level in the testis was higher, on the whole, than in the liver and kidney. The glutathione level did not differ significantly among any of the treatment groups (Fig. 2(C)).

\section{Discussion}

Lipid peroxidation has been implicated in a potential cause of chronic lifestyle-related diseases such as arteriosclerosis, diabetes and cancer. Therefore, clarification of the suppressive mechanisms reducing dietary DHA-induced lipid peroxide formation is important from the viewpoint of safety, and such study is also necessary to improve the physiological efficacy of $n-3$ PUFA. 
In previous studies (Kubo et al. 2000; Saito \& Kubo, 2003), we found that the production of tissue lipid peroxides was closely associated with the P-index of the total lipids in DHA-fed rats that were almost vitamin E-deficient. In rats exhibiting the vitamin E-deficient state, tissue parenchymal cell injuries were also observed. However, when the rats ingested a typical level of vitamin $\mathrm{E}$ at $54 \mathrm{mg} \alpha$-tocopherol equivalent $/ \mathrm{kg}$ diet (American Institute of Nutrition, 1977, 1980), the dietary DHAinduced lipid peroxide formation did not increase to the level that was expected from the P-index of the total tissue lipids (Kubo et al. 1998, 2000; Saito \& Kubo, 2003). This phenomenon was especially prominent in the liver. Tissue parenchymal cell injuries were also not observed in rats with this vitamin E status (Kubo et al. 2000; Saito \& Kubo, 2003). However, the lipid peroxide formation, particularly in the liver, was not suppressed further, even after a high level of vitamin $\mathrm{E}$ ingestion (Kubo et al. 2000). This result suggested that vitamin $\mathrm{E}$ exerted a limited antioxidant capacity when highly unsaturated DHA was ingested. Moreover, we found (Kubo et al. 1997; Saito \& Kubo, 2003) that the AsA and glutathione levels in the tissues of rats concurrently increased when DHA was ingested. Accordingly, we presumed that this phenomenon could represent one of the mechanisms suppressing tissue lipid peroxide formation below the level expected from the P-index of the total tissue lipids (Kubo et al. 1998, 2000; Saito \& Kubo, 2003). The suppression was also seen with EPA ingestion, but not with $\alpha$-linolenic acid ingestion (Saito \& Kubo, 2003). Therefore, in the present study, we focused on the influence of DHA ingestion and different levels of dietary AsA on tissue lipid peroxidation in genetically scorbutic ODS rats.

In previous studies, we also observed that dietary DHA-stimulated lipid peroxidation was most apparent in the liver, intermediate in the kidney, least observable in the testis (Kubo et al. 2000) and non-observable in the brain (Kubo et al. 1998). Hence, we chose the liver, kidney and testis to examine the effects of dietary AsA and DHA in the present study.

During the feeding period, no rats showed signs of scurvy, e.g. no haemorrhages around the eyes and nose were observed, and the concentrations of AsA did not reach complete depletion in the tissues analysed (Fig. 2). Therefore, none of the rats appeared to have been AsA-deficient.

The plasma $\alpha$-tocopherol concentration was decreased by DHA ingestion (Table 3), similar to previous studies (Saito et al. 1996; Kubo et al. 1997, 1998, 2000). The concentrations in the DHA-fed groups were not influenced by the dietary AsA levels; this result was in agreement with the reports of Cadenas et al. (1996) and Smith et al. (1999), both employing ODS rats under nonscorbutic and normal vitamin E conditions. Therefore, no vitamin E-sparing effect by increased dietary AsA intake was observed in the plasma. Moreover, the plasma lipid peroxide levels were also not suppressed by an increase in AsA intake, although AsA intake of $\geq 600 \mathrm{mg} / \mathrm{kg}$ diet suppressed tissue parenchymal cell injuries, possibly in the liver, as seen in the decreased plasma alanine aminotransferase activity (Table 3 ). Therefore, these results suggested that AsA exerted a limited antioxidant capacity, and also that the highly unsaturated DHA ingestion raised the requirement for AsA as well as vitamin E.

Under an almost vitamin E-deficient state, the liver chemiluminescence intensity was associated with an increase in the liver P-index (Kubo et al. 2000). Under the low AsA conditions in the present study, we observed the phenomenon similar to that under an almost vitamin E-deficient state. The intensities in the DHA-fed groups with $\geq 300 \mathrm{mg} \mathrm{AsA} / \mathrm{kg}$ diet were suppressed below the Pindex (Fig. 1(A)). This phenomenon suggests an antioxidant effect of AsA in the liver. An in vitro study (Benzie et al. 1999) has indicated that antioxidant capacity of AsA was linear up to $1000 \mu \mathrm{M}$-ascorbate, as shown by ferric reducing-antioxidant power assay. However, the lipid peroxide levels in the DHA-fed groups were not further suppressed by the AsA intake $\geq 600 \mathrm{mg} / \mathrm{kg}$ diet. Hence, the in vitro study was different from our present in vivo study in which the higher AsA intake did not suppress further the liver lipid peroxide formation. This difference between in vivo and in vitro studies remains to be explained.

Similarly, the levels of AsA intake would be related to a reductive recycling of vitamin $\mathrm{E}$ and/or vitamin $\mathrm{E}$-sparing effect, although there are contradictory reports that have suggested the vitamin E-sparing effect (Igarashi et al. 1991; Tanaka et al. 1997) and those that have shown evidence against it (Burton et al. 1990). In the present study, the $\alpha$-tocopherol levels in the liver decreased with DHA ingestion, and significantly decreased even further with low AsA intake (Fig. 2(A)). Therefore, the vitamin E-sparing effect may be observable under the low AsA conditions. This phenomenon was in accordance with the reports of in vivo (Tanaka et al. 1997) and in vitro studies (Niki et al. 1984; Scarpa et al. 1984; Halpner et al. 1998a,b; May et al. 1998, 2000; Chepda et al. 2001; Mawatari \& Murakami, 2001). However, the lipid peroxidation induced consumption of vitamin $\mathrm{E}$ was not further suppressed by a large intake of AsA, and thus, these results suggest that AsA exerted a limited antioxidant capacity and also a limited suppression of the effects of vitamin E consumption in the liver. Therefore, factors other than AsA may probably be related to the suppression of lipid peroxide formation to a level below the P-index in the liver.

In the PUFA composition of the kidney (Table 2), the proportions of $n-6$ PUFA were generally higher, and that of DHA was lower, than in the liver. In addition, high retroconversion from DHA to EPA was shown in the kidney, as already recognized (Saito et al. 1998). Because of these characteristic profiles of PUFA in the kidney, the increase in the P-index seemed to be modest, even after the highly unsaturated DHA was ingested. Accordingly, the increase in the lipid peroxide levels in the kidney was moderate, and nearly coincided with the increase in the P-index, irrespective of the dietary AsA levels (Fig. 1(B)). We presume, therefore, that dietary AsA in excess of normal levels is not significantly related to suppressing lipid peroxide formation in the kidney.

The proportion of $n-6$ PUFA in the testis was remarkably high even after the highly unsaturated DHA was ingested (Table 2). This phenomenon, namely preferential incorporation and/or synthesis of $n-6$ PUFA in 
the testis, may regulate the increases in the P-index and lipid peroxide levels. Thus, the lipid peroxide formation nearly coincided with the P-index, regardless of the dietary AsA levels. Therefore, we thought that AsA was hardly involved in the suppression of testis lipid peroxide formation with highly unsaturated DHA ingestion.

The methods used in the present study to measure lipid peroxidation products were indirect, and so there are limitations in such measurements as compared with the direct methods using HPLC, immunological techniques, GC-MS and so on. However, Cadenas et al. (1996) showed that dietary vitamin $\mathrm{E}$ decreased lipid peroxidation in the liver and plasma as measured by TBARS, as well as by highly specific phosphatidylcholine and phosphatidylethanolamine hydroperoxides using HPLC-chemiluminescence analyser. Therefore, the TBARS levels measured in the present study may be correlated with phosphatidylcholine and phosphatidylethanolamine hydroperoxide levels. We are now establishing direct methods to measure phosphatidylcholine and phosphatidylethanolamine hydroperoxides using HPLC-chemiluminescence analyser, as well as to measure degradation products of lipid peroxidation, aldehydes, using immunological techniques. Results obtained from such direct measurements are necessary to verify our hypothesis so far proposed.

In conclusion, when highly unsaturated DHA was given to genetically scorbutic ODS rats, dietary AsA levels $>300 \mathrm{mg} / \mathrm{kg}$ diet did not further suppress lipid peroxide formation and concentration of vitamin $\mathrm{E}$ in the liver. In addition, the higher intake of AsA also did not further suppress lipid peroxide formation in the kidney and testis. Therefore, other factors, including glutathione, but not AsA, may be related to the mechanisms that suppress DHA-stimulated liver lipid peroxide formation to the level below that expected from the P-index of the total liver lipids.

\section{Acknowledgements}

We gratefully acknowledge the technical assistance of Miss Sayaka Ishikawa. We thank Maruha Corporation, Japan, for the generous gift of the DHA concentrate.

\section{References}

American Institute of Nutrition (1977) Report of the American Institute of Nutrition ad hoc committee on standards for nutritional studies. J Nutr 107, 1340-1348.

American Institute of Nutrition (1980) Second report of ad hoc committee on standards for nutritional studies. J Nutr $\mathbf{1 1 0}$ 1726.

Atwater WO (1902) Principles of Nutrition and Nutritive Value of Food. US Department of Agriculture Farmers' Bulletin no. 142, 2nd revision, pp. 48. Beltsville, MD: US Department of Agriculture.

Benzie IFF, Chung WY \& Strain JJ (1999) "Antioxidant" (reducing) efficiency of ascorbate in plasma is not affected by concentration. $J$ Nutr Biochem 10, 146-150.

Beutler E, Duron O \& Kelly BM (1963) Improved method for the determination of blood glutathione. J Lab Clin Med 61, $882-888$.
Bligh EG \& Dyer WJ (1959) A rapid method of total lipid extraction and purification. Can J Biochem Physiol 37, 911-917.

Boveris A, Cadenas E \& Chance B (1981) Ultraweak chemiluminescence: a sensitive assay for oxidative radical reactions. Fed Proc 40, 195-198.

Burton GW, Wronska U, Stone L, Foster DO \& Ingold KU (1990) Biokinetics of dietary RRR-alpha-tocopherol in the male guinea pig at three dietary levels of vitamin $\mathrm{C}$ and two levels of vitamin E. Evidence that vitamin C does not "spare" vitamin $\mathrm{E}$ in vivo. Lipids 25, 199-210.

Cadenas S, Lertsiri S, Otsuka M, Barja G \& Miyazawa T (1996) Phospholipid hydroperoxides and lipid peroxidation in liver and plasma of ODS rats supplemented with $\alpha$-tocopherol and ascorbic acid. Free Radic Res 26, 485-493.

Chakraborty S, Nandi A, Mukhopadhyay M, Mukhopadhyay CK \& Chatterjee IB (1994) Ascorbate protects guinea pig tissues against lipid peroxidation. Free Radic Biol Med 16, 417-426.

Chepda T, Cadau M, Lassabiliere F, Reynaud E, Perier C, Frey J \& Chamson A (2001) Synergy between ascorbate and alphatocopherol on fibroblasts in culture. Life Sci 69, 1587-1596.

Cosgrove JP, Church DF \& Pryor WA (1987) The kinetics of the autoxidation of polyunsaturated fatty acids. Lipids $\mathbf{2 2}$, 299-304.

Dixon WJ \& Massey FJ Jr (1983) Inference: Two populations. In Introduction to Statistical Analysis, pp. 116-131 [WJ Dixon and FJ Massey Jr, editors]. New York: McGraw-Hill.

Dyerberg J (1986) Linolenate-derived polyunsaturated fatty acids and prevention of atherosclerosis. Nutr Rev 44, 125-134.

Fletcher BL, Dillard CJ \& Tappel AL (1973) Measurement of fluorescent lipid peroxidation products in biological systems and tissues. Anal Biochem 52, 1-9.

Folch J, Lees M \& Sloane-Stanley GA (1957) A simple method for isolation and purification of total lipides from animal tissues. J Biol Chem 226, 497-507.

Halpner AD, Handelman GJ, Belmont CA, Harris JM \& Blumberg JB (1998a) Protection by vitamin C of oxidantinduced loss of vitamin $\mathrm{E}$ in rat hepatocytes. $J$ Nutr Biochem 9, 355-359.

Halpner AD, Handelman GJ, Harris JM, Belmont CA \& Blumberg JB (1998b) Protection by vitamin C of loss of vitamin E in cultured rat hepatocytes. Arch Biochem Biophys 359, 305-309.

Hammer CT \& Wills ED (1978) The role of lipid components of the diet in the regulation of the fatty acid composition of the rat liver endoplasmic reticulum and lipid peroxidation. Biochem $J$ 174, 585-593.

Harris WS (1989) Fish oils and plasma lipid and lipoprotein metabolism in humans: a critical review. J Lipid Res 30, 785-807.

Herold PM \& Kinsella JE (1986) Fish oil consumption and decreased risk of cardiovascular disease: a comparison of findings from animal and human feeding trials. Am J Clin Nutr 43, 566-598.

Holmgren A \& Björnstedt M (1995) Thioredoxin and thioredoxin reductase. Methods Enzymol 252, 199-208.

Horio F, Ozaki K, Yoshida A, Makino S \& Hayashi Y (1985) Requirement for ascorbic acid in a rat mutant unable to synthesize ascorbic acid. $J$ Nutr 115, 1630-1640.

Hu M-L, Frankel EN, Leibovitz BE \& Tappel AL (1989) Effect of dietary lipids and vitamin $\mathrm{E}$ on in vitro lipid peroxidation in rat liver and kidney homogenates. J Nutr 119, 1574-1582.

Igarashi O, Yonekawa Y \& Fujiyama-Fujiwara Y (1991) Synergistic action of vitamin $\mathrm{E}$ and vitamin $\mathrm{C}$ in vivo using a new mutant of Wistar-strain rats, ODS, unable to synthesize vitamin C. J Nutr Sci Vitaminol 43, 435-444. 
Kawai T, Nishikimi M, Ozawa T \& Yagi K (1992) A missense mutation of L-gulono- $\gamma$-lactone oxidase causes the inability of scurvy-prone osteogenic disorder rats to synthesize L-ascorbic acid. J Biol Chem 267, 21973-21976.

Kimura H, Yamada Y, Morita Y, Ikeda H \& Matsuo T (1992) Dietary ascorbic acid depresses plasma and low density lipoprotein lipid peroxidation in genetically scorbutic rats. J Nutr 122, 1904-1909.

Kobatake Y, Hirahara F, Innami S \& Nishide E (1983) Dietary effect of $\omega-3$ type polyunsaturated fatty acids on serum and liver lipid levels in rats. J Nutr Sci Vitaminol 29, 11-21.

Kristensen SD, Bach Iversen AM \& Schmidt EB (2001) n-3 Polyunsaturated fatty acids and coronary thrombosis. Lipids 36, S79-S82.

Kubo K, Saito M, Tadokoro T \& Maekawa A (1997) Changes in susceptibility of tissues to lipid peroxidation after ingestion of various levels of docosahexaenoic acid and vitamin E. $\mathrm{Br} J$ Nutr 78, 655-669.

Kubo K, Saito M, Tadokoro T \& Maekawa A (1998) Dietary docosahexaenoic acid dose not promote lipid peroxidation in rat tissue to the extent expected from peroxidizability index of the lipids. Biosci Biotechnol Biochem 62, $1698-1706$.

Kubo K, Saito M, Tadokoro T \& Maekawa A (2000) Preferential incorporation of docosahexaenoic acid into nonphosphorus lipids and phosphatidylethanolamine protects rats from dietary DHA-stimulated lipid peroxidation. J Nutr 130, 1749-1759.

Lowry OH, Rosebrough NJ, Farr AL \& Randall RJ (1951) Protein measurement with the Folin phenol reagent. J Biol Chem 193, 265-275.

Mawatari S \& Murakami K (2001) Effect of ascorbate on membrane phospholipids and tocopherols of intact erythrocytes during peroxidation by $t$-butylhydroperoxide: comparison with effects of dithiothreitol. Lipids 36, 57-65.

May JM, Qu ZC, Marrow JD \& Cobb CE (2000) Ascorbatedependent protection of human erythrocytes against oxidant stress generated by extracellular diazobenzene sulfonate. Biochem Pharmacol 60, 47-53.

May JM, Qu ZC \& Mendiretta S (1998) Protection and recycling of $\alpha$-tocopherol in human erythrocytes by intracellular ascorbic acid. Arch Biochem Biophys 349, 281-289.

Miyazawa T, Tsuchida K \& Kaneda T (1984) Riboflavin tetrabutyrate: an antioxidative synergist of alpha-tocopherol as estimated by hepatic chemiluminescence. Nutr Rep Int $\mathbf{2 9}$, $157-165$.

Mouri K, Ikesue H, Esaka T \& Igarashi O (1984) The influence of marine oil intake upon levels of lipids, $\alpha$-tocopherol and lipid peroxidation in serum and liver of rats. J Nutr Rep Int 30, 307-318.

Niki E, Saito T, Kawakami A \& Kamiya Y (1984) Inhibition of oxidation of methyl linoleate in solution by vitamin $\mathrm{E}$ and vitamin C. J Biol Chem 259, 4177-4182.

Ohkawa H, Ohishi N \& Yagi K (1979) Assay for lipid peroxides in animal tissues by thiobarbituric acid reaction. Anal Biochem 95, 351-358.

Pietrangelo A, Grandi R, Tripodi A, et al. (1990) Lipid composition and fluidity of liver mitochondria, microsomes and plasma membrane of rats with chronic dietary iron overload. Biochem Pharmacol 39, 123-128.

Rao KS \& Recknagel RO (1968) Early onset of lipid peroxidation in rat liver after carbon tetrachloride administration. Exp Mol Pathol 9, 271-278.

Reitman S \& Frankel S (1957) A colorimetric method for the determination of serum glutamic oxaloacetic and glutamic pyruvic transaminase. Am J Clin Pathol 28, 56-63.

Roe JH, Mills MB, Oesterling MJ \& Damron CM (1948) The determination of diketo-1-gulonic acid, dihydro-1-ascorbic acid, and 1-ascorbic acid in the same tissue extract by the 2,4-dinitrophenyl-hydrazine method. J Biol Chem 174, 201-208.

Saito M \& Kubo K (2003) Relationship between tissue lipid peroxidation and peroxidizability index after $\alpha$-linolenic, eicosapentaenoic, or docosahexaenoic acid intake in rats. $B r J$ Nutr 89, 19-28.

Saito M, Kubo K \& Ikegami S (1996) An assessment of docosahexaenoic acid (DHA) intake with special reference to lipid metabolism in rats. J Nutr Sci Vitaminol 42, 195-207.

Saito M, Nakatsugawa K, Oh-hashi A, Nishimuta M \& Kodama N (1992) Comparison of vitamin E levels in human plasma, red blood cells, and platelets following varying intakes of vitamin E. J Clin Biochem Nutr 12, 59-68.

Saito M, Ueno M, Kubo K \& Yamaguchi M (1998) Doseresponse effect of dietary docosahexaenoic acid on fatty acid profiles of serum and tissue lipids in rats. J Agric Food Chem 46, 184-193.

Saito M \& Yamaguchi M (1988) Influence of excessive ascorbic acid dose on liver microsomal mixed function oxidase system in guinea pigs. J Clin Biochem Nutr 4, 123-137.

Scarpa M, Rigo A, Maiorino M, Ursini F \& Gregolin C (1984) Formation of alpha-tocopherol radical and recycling of alphatocopherol by ascorbate during peroxidation of phosphatidylcholine liposomes. An electron paramagnetic resonance study. Biochim Biophys Acta 801, 215-219.

Schmidt EB, Christensen JH, Aardestrup I, Madsen T, Riahi S, Hansen VE \& Skou HA (2001) Marine $n-3$ fatty acids: basic features and background. Lipids 36, S65-S68.

Simopoulos AP (1991) Omega-3 fatty acids in health and disease and in growth and development. Am J Clin Nutr 54, 438-463.

Smith D, Shang F, Nowell TR, et al. (1999) Decreasing ascorbate intake does not affect the levels of glutathione, tocopherol or retinol in the ascorbate-requiring osteogenic disorder shionogi rats. J Nutr 129, 1229-1232.

Song JH, Fujimoto K \& Miyazawa T (2000) Polyunsaturated $(n-3)$ fatty acids susceptible to peroxidation are increased in plasma and tissue lipids of rats fed docosahexaenoic acid-containing oils. J Nutr 130, 3028-3033.

Tanaka K, Hashimoto T, Tokumaru S, Iguchi H \& Kojo S (1997) Interactions between vitamin C and vitamin $\mathrm{E}$ are observed in tissues of inherently scorbutic rats. J Nutr 127, 2060-2064.

Tsuchida M, Miura T, Mizutani K \& Aibara K (1985) Fluorescent substances in mouse and human sera as a parameter of in vivo lipid peroxidation. Biochim Biophys Acta 834, 196-204.

Wartanowicz M, Panczenko-Kresowska B, Ziemlańkski Ś, Kowalska M \& Okolska G (1984) The effect of $\alpha$-tocopherol and ascorbic acid on the serum lipid peroxide level in elderly people. Ann Nutr Metab 28, 186-191.

Wells WW, Xu DP \& Washburn MP (1995) Glutathione: dehydroascorbate oxidoreductases. Methods Enzymol 252, 30-38.

Yagi K (1976) A simple fluorometric assay for lipoperoxide in blood plasma. Biochem Med 15, 212-216. 